\title{
Evidence for Resource Homogenization in 50 Trophic Ecosystem Networks
}

\author{
S.R. Borrett*, A.K. Salas \\ Department of Biology \& Marine Biology and Center for Marine Science, University of North Carolina Wilmington, 601 S. College Rd., \\ Wilmington, $28403 \mathrm{NC}$, USA
}

\begin{abstract}
Connectivity patterns of ecological elements are often the core concern of ecologists working at multiple levels of organization (e.g., populations, communities, ecosystems, and landscapes) because these patterns often reflect the forces shaping the system's development as well as constraining their operation. One reason these patterns of direct connections are critical is that they establish the pathways through which elements influence each other indirectly. Here, we tested a hypothesized consequence of connectivity in ecosystems: the homogenization of resource distributions in flow networks. Specifically, we tested the generality of the systems ecology hypothesis of resource homogenization in 50 empirically derived trophic ecosystem models representing 35 distinct ecosystems. We applied Network Environ Analysis (NEA) to calculate resource homogenization for these models, where homogenization is defined as the ratio of the coefficient of variation of the direct flow intensity matrix $(C V(\mathbf{G}))$ to the covariance of the integral flow intensity matrix $(C V(\mathbf{N}))$. A ratio greater than unity indicates the presence of homogenization. We also tested the hypotheses that homogenization increases with system size, connectance, and cycling. We further evaluated the robustness of our results in two ways. First, we verified the close correspondence between the input- and output-oriented homogenization values to ensure T) that our results were not biased by our decision to focus on the output orientation. Second, we conducted a Monte Carlo based uncertainty analysis to determine the robustness of our results to $\pm 5 \%$ error introduced into the original flow matrices for each model. Our results show that resource homogenization occurs universally in the 50 ecosystem models tested, with values ranging from 1.04 to 1.97 and a median of 1.61. However, our results do not support the hypothesized relationship between network homogenization and system size and connectance, as the results of the linear regressions are insignificant. Further, there is only weak support for the positive relationship between homogenization and cycling. We confirm that our results are not biased by using the output-oriented homogenization values instead of the input-oriented values because there is a significant linear regression between the two types of homogenization $\left(r^{2}=0.38, p<0.001\right)$ and the values are well correlated $(S=8,054, \rho=0.61, p<0.001)$. Finally, we found that our results are robust to $\pm 5 \%$ error in the flow matrices. The error in the homogenization values was less than the error introduced into the models and ranged from a minimum of $0.24 \%$ to a maximum of $1.5 \%$ with a median value of $0.58 \%$. The error did not change the qualitative interpretation of the homogenization values. In conclusion, we found strong support for the resource homogenization hypothesis in 50 empirically derived ecosystem models.
\end{abstract}

Keywords: network environ analysis, indirect effects, input-output analysis, network homogenization, connectivity, food web, ecological network analysis

"It is a recognized principle of ecology that the interactions of organisms and their environment are reciprocal" Redfield (1958)

\section{Introduction}

Connectivity is a core concept in ecology. This is evident in Redfield's (1958) opening quote, but other examples include Darwin's (1959) entangled bank metaphor, exploiter-victim spatial connectivity (Holland and Hastings, 2008), landscape ecology (Urban and Keitt, 2001),

\footnotetext{
*Corresponding author. Tel. 910.962.2411; fax: 910.962.4066 Email addresses: borretts@uncw.edu (S.R. Borrett), aks2515@uncw.edu (A.K. Salas)
}

and community interactions (Jordán et al., 2003). John Muir solidified this idea in the public imagination with his statement that "When we try to pick out anything by itself, we find that it is bound fast by a thousand invisible cords that cannot be broken to everything in the universe" (as quoted by Fox, 1981, p. 291).

Too often this principle idea is dismissively summarized as: "Everything is connected to everything else". As Peters (1991) pointed out, this statement is vacuous; there is no way to determine if this statement is true or false. Perhaps more importantly, however, it misses the fundamental point. In ecological systems, as well as other types of complex systems, how organisms and their environmental components are connected is what is interesting. For example, Jordano et al. (2003) suggest that the nestedness 
pattern commonly found in mutualistic networks may facilitate coevolutionary interactions. Dunne et al. (2002) found increasing food web connectivity tends to increase ecosystem robustness to biodiversity loss, but this effect was modulated in part by the pattern of node degree distributions. These connectivity patterns reflect the processes that create and constrain a system's development, its function and the services it provides. In this paper, we investigated a hypothesized consequence of network connectivity in ecosystems, the systems ecology hypothesis that "the action of networks makes the distribution of resources more uniform", which is termed network homogenization (Patten et al., 1990; Fath and Patten, 1999a; Jørgensen et al., 2007).

The network homogenization hypothesis emerged from the development and application of Network Environ Analysis (NEA), one type of ecological network analysis derived from the application and extension of Leontief's (1966) economic input-output analysis (see review by Fath and Patten, 1999b). Patten et al. (1990) noticed that when they applied NEA to ecosystem models, the distribution of integral flow intensities (the combination of boundary, direct, and indirect flow intensities) tended to be more even than the distribution of direct flow intensities alone. This change in distribution was hypothesized to be a consequence of the indirect relationships that depend in part on the connectivity pattern (Borrett et al., 2007, in press.).

Fath and Patten (1999a) introduced a method of quantifying network homogenization that is now a standard part of NEA (Fath and Borrett, 2006; Fath and Patten, 1999b). Subsequently, Fath (2004) and Fath and Killian (2007) found evidence that network homogenization occurred regularly in large hypothetical ecosystem networks, and it tended to increase with energy-matter recycling as well as network size. In contrast to these hypothetical models, however, there have been comparatively few applications of this analysis to empirically-based ecosystem models (but see Fath and Patten, 1999a; Borrett and Osidele, 2007; Gattie et al., 2006; Baird et al., 2009).

The objective of the work reported here was to to determine the evidence for the network homogenization hypothesis in empirically-based ecosystem models. Specifically, we tested two hypotheses. First, we examined the generality of the occurrence of network homogenization in 50 empirically-based trophic ecosystem models. Second, we tested the hypothesized relationship between network homogenization and network order, connectance degree, and the magnitude of recycling. We concluded by considering the ecological consequences of this type of connectivity in ecosystem networks.

\section{Materials and Methods}

\subsection{Models}

For this meta-analysis we used a database of 50 ecosystem network models that represent 35 distinct primarily freshwater and marine ecosystems (Table 1). The models exhibit a range of sizes $(4 \leq n \leq 125)$, connectance (number of direct links divided by the total possible number of links; $\left.0.03 \leq\left(C=L / n^{2}\right) \leq 0.40\right)$, and recycling $(0 \leq F C I \leq 0.51)$. At the core of these trophically-based networks is a food web; however, any ecological processes that transfers energy-matter are considered including natural mortality, excretion, and respiration. Furthermore, detritus and several other non-living pools of carbon (e.g., dissolved organic matter) are usually key components of the models.

These ecosystem models are empirically derived and generally meet the network construction criteria of Fath et al. (2007). We designate them as empirically based because empirical estimates were made to quantify some number of the energy-matter fluxes; however, they are heterogeneous with respect to their degree of empirical quantification and resolution. Sometimes to complete the model estimates were made from similar systems or generalities, rather than the specific system observed (e.g. Brylinsky, 1972). Despite this variability, we claim that these models are empirically based by contrast to nonempirically based ecosystem models such as the hypothetical models of Webster et al. (1975) or the cyber-models built from general ecosystem assembly rules like those of Fath (2004).

\subsection{Network Environ Analysis and Homogenization}

Our study uses Network Environ Analysis (NEA), which is well described in the literature (e.g., Patten et al., 1976; Fath and Patten, 1999b; Fath and Borrett, 2006). We introduce aspects of the output oriented throughflow analysis most relevant to the work presented.

NEA is applied to a network model of energy-matter storage and flux in ecosystems. In this model, $n$ nodes represent species, groups of species, or abiotic components and the $L$ weighted directed edges represent the flow of energy-matter generated by some ecological process (e.g., photosynthesis, consumption, excretion, harvesting, and respiration). Let $\mathbf{F}_{n \times n}=\left(f_{i j}\right)$ represent the observed flow from ecosystem compartment $j$ to compartment $i$ (e.g., $j \rightarrow i), \vec{z}_{n \times 1}$ be a vector of node inputs originating from outside the system, and $\vec{y}_{1 \times n}$ be a vector of flows from each node that exit the system. This network model is like a road map for the transportation of energy or nutrients through the ecosystem. To apply NEA to the models, we usually assume they are at a static, steady-state (balanced inputs and outputs, but see Finn, 1980; Shevtsov et al., 2009, for possible ways to relax these assumptions). To meet this analytical assumption, we balanced 22/50 models in our data set that were not initially at steady state with the AVG2 algorithm (Allesina and Bondavalli, 2003).

Given this model input, our analysis starts with three main calculations. First, we determine the throughflow vector $\vec{T}$, which is the total amount of energy-matter flowing into or out of each node. This can be calculated from 
the model information as follows:

$$
\begin{aligned}
\vec{T}^{\text {in }} & =\sum_{j=1}^{n} f_{i j}+z_{i}, \text { and } \\
\vec{T}^{\text {out }} & =\sum_{i=1}^{n} f_{i j}+y_{j} .
\end{aligned}
$$

At steady state, $\vec{T}^{\text {in }}=\left(\vec{T}^{\text {out }}\right)^{\mathrm{T}}=\vec{T}_{n \times 1}=\left(T_{j}\right)$. From this vector, we derive the first whole-system indicator, total system throughflow $\left(T S T=\sum_{i=1}^{n} \vec{T}\right) . T S T$ indicates the magnitude of flow activity in the system and is similar in concept to the gross domestic product from economics.

The second calculation determines the direct flow intensities, $\mathbf{G}_{n \times n}=\left(g_{i j}\right)$ from node $j$ to $i$. These are

$$
\mathbf{G}=\left(g_{i j}\right)=f_{i j} / T_{j} .
$$

Notice that the elements of $\mathbf{G}$ are unitless and that the column sums must lie between zero and unity because ecosystems are open thermodynamic systems (Jørgensen et al., 1999).

The final step is to determine the integral flow intensities, $\mathbf{N}_{n \times n}=\left(n_{i j}\right)$. These $n_{i j}$ represent the intensity of boundary flow that passes from $j$ to $i$ over all pathways of all lengths. These values integrate the boundary, direct, and indirect flows, and are determined as

$$
\mathbf{N}=\sum_{m=0}^{\infty} \mathbf{G}^{m}=\underbrace{\mathbf{I}}_{\text {Boundary }}+\underbrace{\mathbf{G}^{1}}_{\text {Direct }}+\underbrace{\mathbf{G}^{2}+\ldots+\mathbf{G}^{m}+\ldots}_{\text {Indirect }}
$$

In equation (4), $\mathbf{I}=\left(i_{i j}\right)=\mathbf{G}^{0}$ is the matrix multiplicative identity, and the elements of $\mathbf{G}^{m}$ are the flow intensities from $j$ to $i$ over all pathways of length $m$. For example, the pathway $j \rightarrow k \rightarrow i$ would have a length $m=2$. We can find the exact values of $\mathbf{N}$ because the power series converges so that

$$
\mathbf{N}=(\mathbf{I}-\mathbf{G})^{-1} .
$$

Multiple manipulations of the $\mathbf{G}$ and $\mathbf{N}$ matrices have been made in NEA (Fath and Borrett, 2006; Schramski et al., 2006), but here we are most concerned with network homogenization. Fath and Patten (1999a) suggested we could use the ratio of the coefficients of variation in $\mathbf{G}$ and $\mathbf{N}$ to quantify the homogenization of resources hypothesized to occur over the longer pathways captured in the integral matrix. Network homogenization is defined as

$$
H M G \equiv \frac{C V(\mathbf{G})}{C V(\mathbf{N})} .
$$

$C V(\mathbf{G})$ and $C V(\mathbf{N})$ represent the standard deviation of the elements in the matrices divided by the mean of the matrix elements. Fath and Patten (1999a) showed algebraically that $C V(\mathbf{N})$ scales between 0 and $n$, but $C V(\mathbf{G})$ should be less than $n$. The $H M G$ ratio has the nice prop- erty of indicating how much more evenly the resources are spread across the flows when indirect pathways are considered relative to the initial distribution in the direct flow intensity matrix. If $H M G$ is greater than unity, we conclude the network has homogenized the resource distribution. We also consider $C V(\mathbf{N})$ to compare the raw differences in resource homogenization between the network models.

\subsection{Uncertainty Analysis}

To determine the robustness of our results, we tested the uncertainty of the NEA homogenization parameter in response to potential error in the data used to construct the models. We used a Monte Carlo type perturbation procedure for this analysis. For each of the 50 models in our database, we constructed a set of perturbed models by randomly (uniform distribution) altering the values in the initial $\mathbf{F}$ matrix by $\pm 5 \%$. Following these changes, the values of the output vector $\vec{y}$ were modified as necessary to re-balance the models. If a negative $\vec{y}$ value was required, the candidate perturbed model was considered a failure because the data must be non-negative for these ecosystem models. Candidate models were generated until 10,000 successful perturbed models were created. We verified that the variation in the successful 10,000 models was $\pm 5 \%$, and then calculated the NEA homogenization parameter for these models. To determine the impact of the $\pm 5 \%$ error in the flow values, we characterized the resultant distribution of the $H M G$ indicator. We chose not to alter the input vector $\vec{z}$ and used a flux perturbation technique that would minimize the change to the original model weighted degree distributions.

\section{Results}

Our results provide strong evidence for the network homogenization hypothesis. The homogenization ratio was larger than unity in all models analyzed (Figure 1a). The minimum, median, and maximum values are 1.04, 1.61, and 1.97, respectively. This indicates that the elements of the integral flow intensity matrix $\mathbf{N}$ are relatively more similar than the elements of the direct flow intensity matrix $\mathbf{G}$ in all 50 models. Indirect flows distribute the resource flows throughout the system.

Figure $1 \mathrm{~b}$ reveals that although resource homogenization is happening, a large amount of variability in integral flow intensities in the models remains. The coefficient of variation in the integral flow matrices ranged from 1.07 in the Oyster Reef model to 6.21 in the Lake Quinte model after the zebra mussel (Dreissena polymorpha) invasion.

Figure 2 shows no clear relationship between the degree of network homogenization and the model number of nodes or degree of connectance. Simple linear regression for $H M G$ versus model size $n\left(F=3.65, r^{2}=0.07, p=\right.$ $0.062)$ and model connectance $C,\left(F=0.74, r^{2}=0.02\right.$, $p=0.39)$ are not statistically significant. Homogenization 


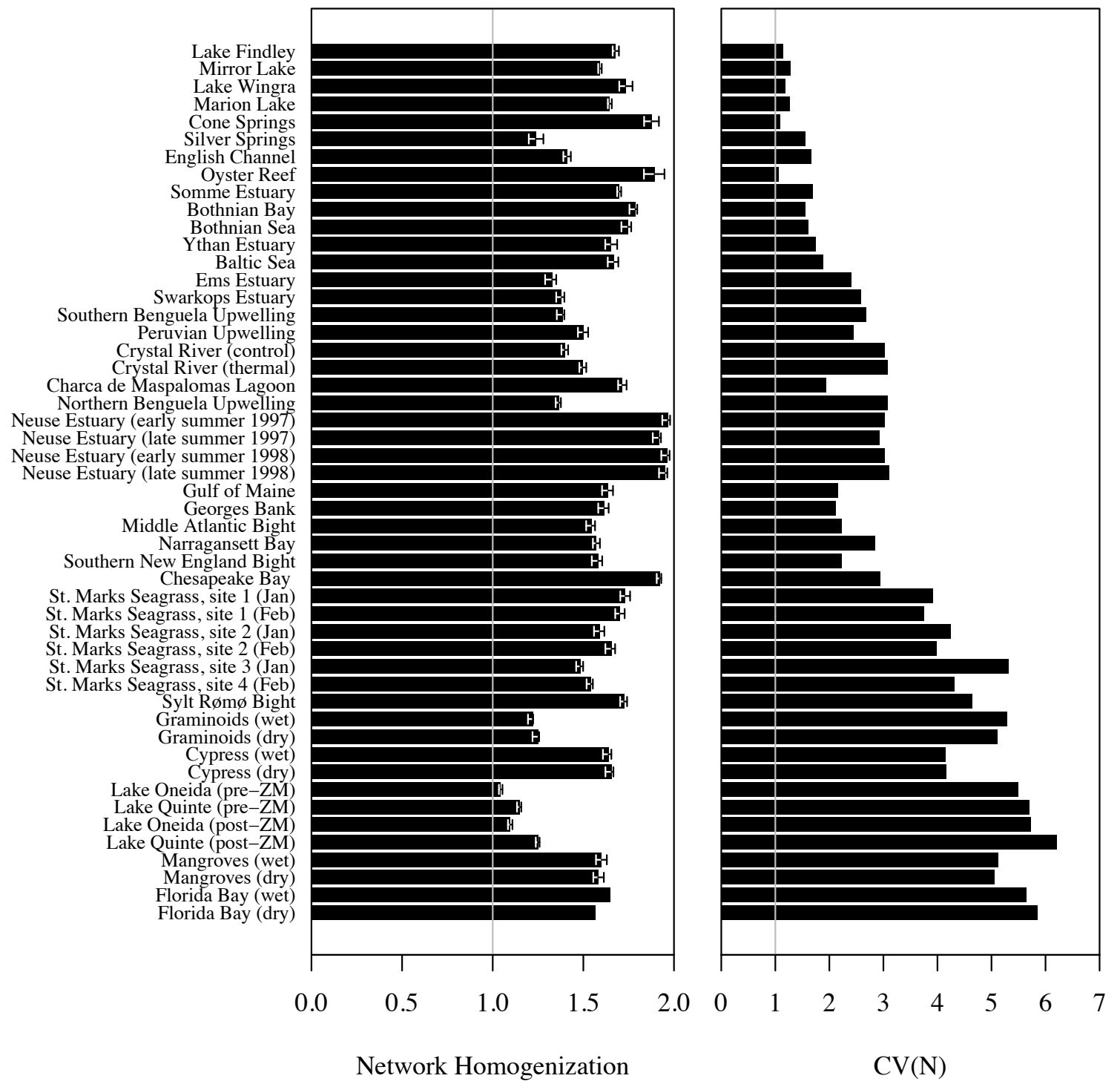

Figure 1: The degree of resource homogenization in 50 trophically-based ecosystem models. Panel (a) shows the network homogenization index $H M G$, while (b) reports the coefficient of variation for the elements of the integral flow intensity matrix $\mathbf{N}$, which is the denominator of $H M G$. Error bars in (a) show the range of $H M G$ values for 10,000 perturbations $( \pm 5 \%)$ of each empirically based ecosystem model.

does seem to increase with the Finn cycling index FCI; however, the shape of the relationship is not well resolved. The relationship does not appear to be linear as a linear regression model violates the assumption of residual homoscedasticity. $F C I$ and $H M G$ are significantly correlated (Spearman's $S=11,355, \rho=0.45, p<0.001$ ), but this significance disappears when we exclude the four models with an FCI less than 0.01 so it may be driven by outlying data points.

Many recent NEA studies have presented either the input- or output-oriented NEA analyses in an effort to simplify the papers. The authors usually claim the results will be qualitatively similar using either orientation. Figure 3 shows this assumption to be generally true for the network homogenization parameter. We found that a statistically significant linear regression fits the data (input $=0.69^{*}$ out- put $+0.64, p<0.001)$. However, it does not explain much of the variation as the adjusted $r^{2}$ was only 0.38 . Despite this, a Spearman Rank correlation test shows that the values are statistically well correlated $(S=8,054, \rho=0.61$, $p<0.001)$.

Our uncertainty analysis suggests the NEA homogenization parameter is robust to the $\pm 5 \%$ variation added to the internal system fluxes $\mathbf{F}$. The error bars in Figure 1 show the distance between the minimum and maximum of the 10,000 $H M G$ values of the perturbed models. These ranges tended to be small, with a median and maximum value of 0.04 and 0.11 . We were unable to generate balanced perturbed models for the Florida Bay models because the output vector $\vec{y}$ contained 11 initial zero values, which consistently led to negative values in the modified $\vec{y}$ and failed perturbed models. 

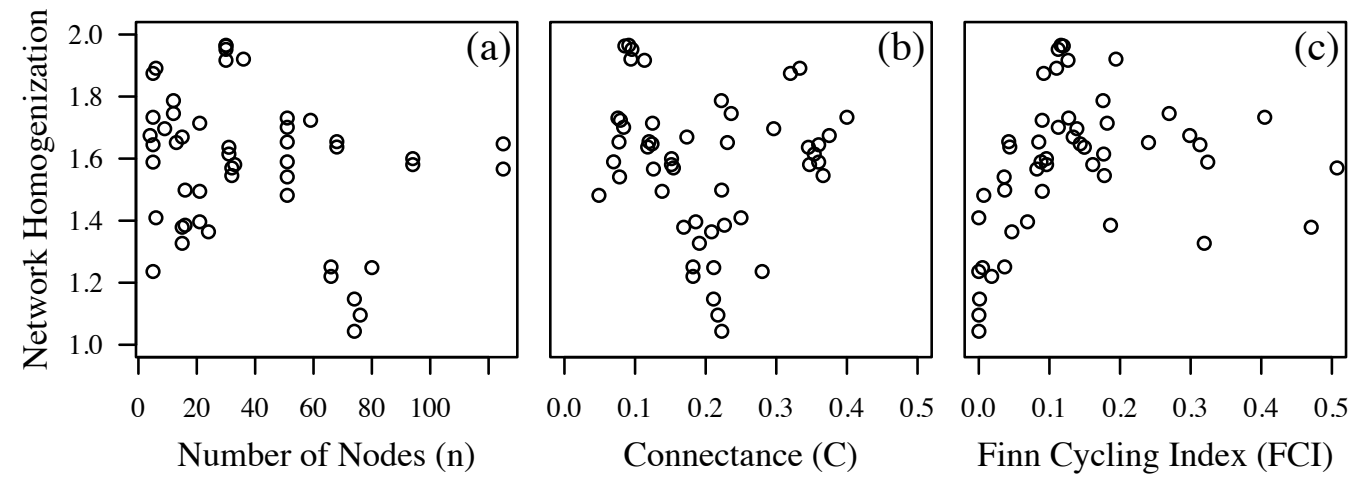

Figure 2: The relationship between output oriented network homogenization and (a) the number of model nodes, $n$, (b) network connectance, $C$, and (c) the Finn Cycling Index, FCI.

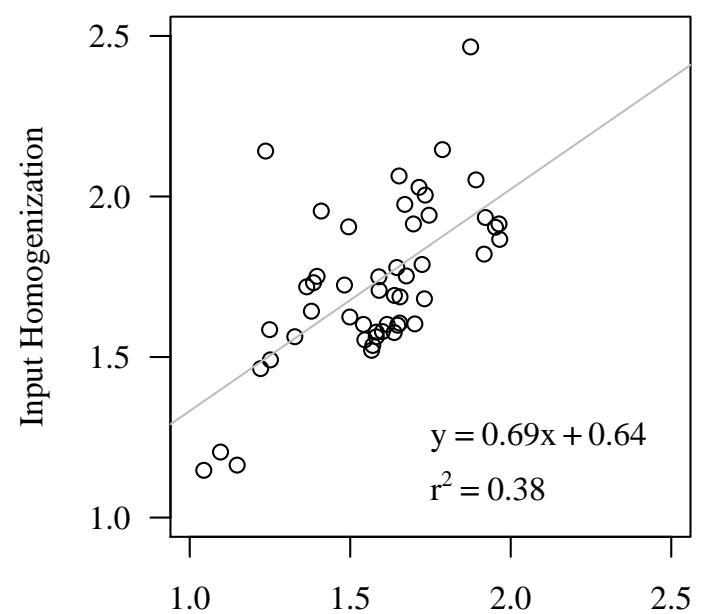

Output Homogenization

Figure 3: The relationship between input and output oriented calculations of network homogenization in 50 trophically-based ecosystem networks. The linear regression is significant with $p<0.001$.

To further estimate the impact of the data uncertainty, we divided the inter-quartile range (distance between first and third quartiles) by the actual homogenization value and multiplied by 100 to get the percent uncertainty. The minimum, median and maximum uncertainties for the model population was $0.24 \%, 0.58 \%$, and $1.5 \%$ respectively. These values are less than the initial $\pm 5 \%$ error introduced into the $\mathbf{F}$ matrix, revealing that the error in the homogenization parameter is generally less than the initial error. Despite the model perturbations, the qualitative interpretation of the homogenization parameter does not change.

\section{Discussion}

The core contribution of this work to systems ecology and ecological network analysis is that we provide evidence for the generality of the network homogenization hypothesis in empirically derived ecosystem models. This hypothesis states that fluxes of resources are more evenly distributed in the network when integral flow intensities (boundary, direct, and indirect) are considered instead of just direct flow intensities. This was universally true in the 50 empirically derived ecosystem models we examined. Further, we found these results to be robust to small perturbations to the original model flux estimates. This suggests that small uncertainties in the original model data would not change the outcome of our analyses. In this section, we discuss the context and ecological significance of these results and conclude by outlining several possible next steps for this research line.

\subsection{Values of Network Homogenization}

Baird et al. (1991) warn against comparing network indicators between models with different structures. This is problematic because different model aggregation schemes as well as other structural features can influence ecological network indicators (Cale and Odell, 1979; Abarca-Arenas and Ulanowicz, 2002; Allesina et al., 2005; Baird et al., 2009). Our goal here is not to compare the individual values of $H M G$, but to provide a broader context to understand the values we observed.

The $H M G$ values for the empirically derived ecosystem models (1.04-1.97) tend to be smaller than those found in previous studies. Fath (2004) found $2<H M G \leq$ 2.8 in hypothetical models based on community assembly rules. This difference in magnitude may be because the community assembly models tended to be larger than the empirically-based models used in this study, though our results do not support the hypothesized relationship between $H M G$ and model size. As suggested by Fath and Killian (2007), this could also be an artifact of the selected pattern of connections in the assembled models. When these authors built community assembly type models that better matched observed food webs the range of $H M G$ values were more similar to those we present. This is further evidence for the importance of carefully considering the patterns of how organisms and their environmental components are connected. The values previously reported for empirically derived models like the Neuse River Estuary, 
2.07 (Gattie et al., 2006), and Lake Sidney Lanier, 3.10 \pm 0.31 (Borrett and Osidele, 2007) are also larger than the values we found. While there are multiple factors that may cause this including the aggregation decisions, these two models are biogeochemically-based networks rather than the trophically-based models we analyzed here. This difference may be another source of variation (Baird et al., 2008; Borrett et al., in press.).

It is surprising that our results do not provide evidence to support the hypothesized positive relationship between $H M G$ and model size $n$ and only weak evidence that it increases with cycling. We suspect this contradiction occurs because our model sample is insufficient to show the expected pattern. The range of model size remains limited (Table 1). However, if this result holds to future scrutiny it might suggest an important characteristic of the more empirically derived models that is not present in Fath's (2004) community assembly models.

The coefficient of variation of the integral flow matrix, the denominator in the resource homogenization ratio (equation 6), shows that despite a tendency for resource homogenization, there remains quite a bit of variability in the integral flow intensity. This variability increases with network size. This pattern is likely driven by the fact that the maximum value of $C V(\mathbf{N})$ increases with model size (see Fath, 2004). We don't observe the same trend with $H M G$ because $C V(\mathbf{G})$ tends to increase with model size at nearly the same rate observed for $C V(\mathbf{N})$. The best fit linear regression of $C V(\mathbf{G})$ and $n$ is $C V(\mathbf{G})=0.07 * n+1.9$ $\left(p<0.001, r^{2}=0.87\right)$ and the linear regression of $C V(\mathbf{N})$ and $n$ is $C V(\mathbf{N})=0.05 * n+0.81\left(p<0.001, r^{2}=0.84\right)$. These trends tend to cancel in the ratio measure.

\subsection{Ecological Significance}

Network homogenization is ecologically significant because it concerns the distribution of resources in the system. As stated in the introduction, resource homogenization implies that regardless of where the resources (e.g., carbon, nitrogen) enter the ecosystem they are more evenly distributed in network models than we might expect from the pattern of direct interactions. Presence of network homogenization suggests that the indirect flows are distributing the model currency (energy-matter) more evenly over the links between organisms and their environs. Thus, the energy-matter may be more or less available to some species than it at first appears. This resource homogenization may lead to a more distributed control in the ecosystems (Schramski et al., 2006, 2007), and transform the effective relationships between species such as apparent predators effectively operating as a net mutualist (Patten, 1991; Ulanowicz and Puccia, 1990).

Resource homogenization is a consequence of the indirect interactions in these networks. Indirect effects are hypothesized to generally be the dominant component of ecological interactions (Higashi and Patten, 1989; Patten, 1991; Borrett et al., 2006, in press.), but this may not hold universally. However, network homogenization suggests that even when indirect effects are not dominant, they may still have important consequences for the ecological and evolutionary interactions in the system. Further, we wonder if there might be a significant difference in $H M G$ between ecosystems classified as healthy and those that are stressed or impacted in some way. We hypothesize that there might be an optimal range of $H M G$ in healthy ecosystems. Too little resource homogenization and the system vigor or activity is under optimized, but too much homogenization and the system becomes crystallized or brittle in the sense of Rapport et al. (1998) and Mageau et al. (1998). This possibility requires further investigation.

\subsection{Limitations and Future Work}

Further work in this research line are key to confirming the theoretical results. These steps can be divided into theoretical and empirical components.

Theoretical developments are required to address the limitations of the work we present. The first issue concerns our sample of ecological models. While we have 50 models that represent 35 distinct systems, this remains a relatively small sample size that needs to be extended as new models become available. Furthermore, many of the models were created by a small set of authors. Thus, our results could be influenced by their conscious or unconscious modeling biases, including how they choose to aggregate species (see Baird et al., 2009). Given the universality of the results, we do not expect this to undermine our conclusions, but it is a potential bias that can be addressed in the future. Another limitation of the models is that they are all trophically-based models of mostly aquatic ecosystems. While we expect the results will hold in more biogeochemically-based ecosystem models as well as more terrestrial ecosystems, this is a testable hypothesis.

Empirical validation of Ecological Network Analysis (ENA) like the NEA results reported here generally remains a challenge for the acceptance and application of the theory (Dame and Christian, 2006, 2008). Part of the challenge is that many of the ENA predictions are simply not directly empirically testable. However, the alignment of ENA results like the dominance of indirect effects (Higashi and Patten, 1989; Borrett and Osidele, 2007; Borrett et al., in press.) and empirical work showing the importance of indirect effects (e.g., Menge, 1995; Wootton, 1991, 1993; Menendez et al., 2007; McCormick, 2009) and initial empirical validation attempts such as that by Dame and Christian (2008) lend credibility to the work. We speculate, however, that the network homogenization hypothesis may be empirically testable using either radio isotopes in experiments like Patten and Witcamp (1967) or stable isotopes in a manner similar to Dame and Christian (2008). Further, we wonder what correspondence might exist between the network homogenization hypothesis and stable isotope mixing models. 


\subsection{Summary}

Our work provides evidence for the generality of the systems ecology network homogenization hypothesis in empirically derived ecosystem models. Homogenization was universal in the models and the results are robust to potential data uncertainty. Together with the initial work of Fath and Patten (1999a) that introduced the quantification and application of the homogenization metric and the work of Fath (2004) and Fath and Killian (2007) that investigated the phenomenon in large ecosystem models built from community assembly rules, this is strong evidence for the hypothesized tendency for network organization to homogenize the distribution of resources in ecosystems. This is an expression of the functional consequences of connectivity patterns in ecosystem ecology.

\section{Acknowledgments}

This research and manuscript benefited from critiques by M. Freeze, A. Stapleton, and S. L. Fann. We would also like to thank D. Baird, J. Link, A. L. J. Miehls and R. E. Ulanowicz for sharing many of their network models with us. Last, we gratefully acknowledge financial support from UNCW (SRB) and the James F. Merritt fellowship from the UNCW Center for the Marine Science (AKS).

\section{References}

Abarca-Arenas, L. G., Ulanowicz, R. E., 2002. The effects of taxonomic aggregation on network analysis. Ecol. Mod. 149, 285-296.

Allesina, S., Bondavalli, C., 2003. Steady state ecosystem flow networks: a comparison between balancing procedures. Ecol. Mod. $165,221-229$.

Allesina, S., Bondavalli, C., Scharler, U. M., 2005. The consequences of the aggregation of detritus pools in ecological networks. Ecol. Mod. 189, 221-232.

Almunia, J., Basterretxea, G., Aistegui, J., Ulanowicz, R. E., 1999. Benthic-pelagic switching in a coastal subtropical lagoon. Estuar. Coast. Shelf S. 49, 221-232.

Baird, D., Asmus, H., Asmus, R., 2004a. Energy flow of a boreal intertidal ecosystem, the Sylt-Rømø bight. Mar. Ecol. Prog. Ser. 279, 45-61.

Baird, D., Asmus, H., Asmus, R., 2008. Nutrient dynamics in the Sylt-Røm $\varnothing$ bight ecosystem, German Wadden Sea: an ecological network analysis approach. Estuar. Coast. Shelf Sci. 80, 339-356.

Baird, D., Christian, R. R., Peterson, C. H., Johnson, G. A., 2004 b. Consequences of hypoxia on estuarine ecosystem function: energy diversion from consumers to microbes. Ecol. App. 14, 805-822.

Baird, D., Fath, B. D., Ulanowicz, R. E., Asmus, H., Asmus, R., 2009. On the consequences of aggregation and balancing of networks on system properties derived from ecological network analysis. Ecol. Mod. 220, 3465-3471.

Baird, D., Luczkovich, J., Christian, R. R., 1998. Assessment of spatial and temporal variability in ecosystem attributes of the St. Marks national wildlife refuge, Apalachee Bay, Florida. Estuar. Coast. Shelf Sci. 47, 329-349.

Baird, D., McGlade, J. M., Ulanowicz, R. E., 1991. The comparative ecology of six marine ecosystems. Philos. Trans. Royal Soc. Lon. B 333, 15-29.

Baird, D., Milne, H., 1981. Energy flow in the Ythan estuary, Aberdeenshire, Scotland. Estuar. Coast. Shelf Sci. 13, 455-472.

Baird, D., Ulanowicz, R. E., 1989. The seasonal dynamics of the Chesapeake Bay ecosystem. Ecol. Monogr. 59, 329-364.
Borrett, S. R., Whipple, S. J., Patten, B. C., Christian, R. R., 2006. Indirect effects and distributed control in ecosystems 3. Temporal variability of indirect effects in a seven-compartment model of nitrogen flow in the Neuse River Estuary (USA) - time series analysis. Ecol. Mod. 194: 178-188.

Borrett, S. R., Fath, B. D., Patten, B.C., 2007. Functional integration of ecological networks through pathway proliferation. J. Theor. Biol. 245: 98-111.

Borrett, S. R., Osidele, O. O., 2007. Environ indicator sensitivity to flux uncertainty in a phosphorus model of Lake Sidney Lanier, USA. Ecol. Mod. 200, 371-383.

Borrett, S. R., Whipple, S. J., Patten, B. C., in press. Rapid development of indirect effects in ecological networks. Oikos.

Brylinsky, M., 1972. Steady-state sensitivity analysis of energy flow in a marine ecosystem. In: Patten, B. C. (Ed.), Systems analysis and simulation in ecology. Vol. Vol.2. Academic Press, pp. 81-101.

Cale, W. G., Odell, P. L., 1979. Concerning aggregation in ecosystem models. In: Halfon, E. (Ed.), Theoretical Systems Ecology. Academic Press, New York, New York, pp. 55-77.

Dame, J. K., Christian, R. R., 2006. Uncertainty and the use of network analysis for ecosystem-based fishery management. Fisheries $31,331-341$.

Dame, J. K., Christian, R. R., 2008. Evaluation of ecological network analysis: validation of output. Ecol. Mod. 210, 327-338.

Dame, R. F., Patten, B. C., 1981. Analysis of energy flows in an intertidal oyster reef. Mar. Ecol. Prog. Ser. 5, 115-124.

Darwin, C., 1959. On the origin of species by means of natural selection. John Murray, London.

Dunne, J. A., Williams, R. J., Martinez, N. D., 2002. Network topology and biodiversity loss in food webs: robustness increases with connectance. Ecol. Let. 5, 558-567.

Fath, B. D., 2004. Network analysis applied to large-scale cyberecosystems. Ecol. Mod. 171, 329-337.

Fath, B. D., Borrett, S. R., 2006. A MATLABC function for network environ analysis. Env. Mod. Soft. 21, 375-405.

Fath, B. D., Killian, M. C., 2007. The relevance of ecological pyramids in community assemblages. Ecol. Mod. 208, 286-294.

Fath, B. D., Patten, B. C., 1999a. Quantifying resource homogenization using network flow analysis. Ecol. Mod. 107, 193-205.

Fath, B. D., Patten, B. C., 1999b. Review of the foundations of network environ analysis. Ecosystems 2, 167-179.

Fath, B. D., Scharler, U. M., Ulanowicz, R. E., Hannon, B., 2007. Ecological network analysis: network construction. Ecol. Mod. 208, 49-55.

Finn, J. T., 1980. Flow analysis of models of the Hubbard brook ecosystem. Ecology 61, 562-571.

Fox, S. R., 1981. John Muir and his legacy: the American conservation movement. Little, Brown, Boston.

Gattie, D. K., Schramski, J. R., Borrett, S. R., Patten, B. C., Bata, S. A., Whipple, S. J., 2006. Indirect effects and distributed control in ecosystems: Network environ analysis of a seven-compartment model of nitrogen flow in the Neuse River estuary, USA-steadystate analysis. Ecol. Mod. 194, 162-177.

Heymans, J. J., Baird, D., 2000. A carbon flow model and network analysis of the northern Benguela upwelling system, Namibia. Ecol. Mod. 126, 9-32.

Higashi, M., Patten, B. C., 1989. Dominance of indirect causality in ecosystems. Am. Nat. 133, 288-302.

Holland, M. D., Hastings, A., 2008. Strong effect of dispersal network structure on ecological dynamics. Nature 456, 792-794.

Jordán, F., Baldi, A., Orci, K. M., Racz, I., Varga, Z., 2003. Characterizing the importance of habitat patches and corridors in maintaining the landscape connectivity of a Pholidoptera transsylvanica (orthoptera) metapopulation. Land. Ecol. 18, 83-92.

Jordano, P., Bascompte, J., Olesen, J. M., 2003. Invariant properties in coevolutionary networks of plant-animal interactions. Ecol. Lett. 6, 69-81.

Jørgensen, S. E., Fath, B. D., Bastianoni, S., Marques, J. C., Müller, F., Nielsen, S., Patten, B. C., Tiezzi, E., Ulanowicz, R. E., 2007. Ecosystems have connectivity. In: A new ecology: systems perspective. Elsevier, Ch. 5, pp. 79-102. 
Jørgensen, S. E., Patten, B. C., Straškraba, M., 1999. Ecosystems emerging: 3. Openness. Ecol. Mod. 117, 41-64.

Leontief, W. W., 1966. Input-Output Economics. Oxford University Press, New York.

Link, J., Overholtz, W., O’Reilly, J., Green, J., Dow, D., Palka, D., Legault, C., Vitaliano, J., Guida, V., Fogarty, M., Brodziak, J., Methratta, L., Stockhausen, W., Col, L., Griswold, C., 2008. The northeast US continental shelf energy modeling and analysis exercise (EMAX): Ecological network model development and basic ecosystem metrics. J. Mar. Sys. 74, 453-474.

Mageau, M. T., Costanza, R., Ulanowicz, R. E., 1998. Quantifying the trends expected in developing ecosystems. Ecol. Mod. 112, $1-22$

McCormick, M. I., 2009. Indirect effects of heterospecific interactions on progeny size through maternal stress. Oikos 118, 744-752.

Menendez, R., Gonzalez-Megias, A., Collingham, Y., Fox, R., Roy, D. B., Ohlemuller, R., Thomas, C. D., 2007. Direct and indirect effects of climate and habitat factors on butterfly diversity. Ecology $88,605-611$.

Menge, B. A., 1995. Indirect effects in marine rocky intertidal interaction webs - patterns and importance. Ecol. Monogr. 65, 21-74.

Miehls, A. L. J., Mason, D. M., Frank, K. A., Krause, A. E., Peacor, S. D., Taylor, W. W., 2009a. Invasive species impacts on ecosystem structure and function: A comparison of Oneida Lake, New York, USA, before and after zebra mussel invasion. Ecol. Mod. 220 (22), 3194-3209.

Miehls, A. L. J., Mason, D. M., Frank, K. A., Krause, A. E., Peacor, S. D., Taylor, W. W., 2009b. Invasive species impacts on ecosystem structure and function: A comparison of the Bay of Quinte, Canada, and Oneida Lake, USA, before and after zebra mussel invasion. Ecol. Mod. 220, 3182-3193.

Monaco, M. E., Ulanowicz, R. E., 1997. Comparative ecosystem trophic structure of three US mid-Atlantic estuaries. Mar. Ecol. Prog. Ser. 161, 239-254.

Odum, H. T., 1957. Trophic structure and productivity of Silver Springs, Florida. Ecol. Monogr. 27, 55-112.

Patten, B., Higashi, M., Burns, T., 1990. Trophic dynamics in ecosystem networks: significance of cycles and storage. Ecol. Mod. 51, $1-28$.

Patten, B., Witcamp, M., 1967. Systems analysis of ${ }^{134}$ cesium kinetics in terrestrial microcosms. Ecology 48, 813.

Patten, B. C., 1991. Network ecology: Indirect determination of the life-environment relationship in ecosystems. In: Higashi, M., Burns, T. (Eds.), Theoretical Studies of Ecosystems: The Network Perspective. Cambridge University Press, New York, pp. 288-351.

Patten, B. C., Bosserman, R. W., Finn, J. T., Cale, W. G., 1976. Propagation of cause in ecosystems. In: Patten, B. C. (Ed.), Systems Analysis and Simulation in Ecology, Vol. IV. Academic Press, New York, pp. 457-579.

Peters, R. H., 1991. A critique for ecology. Cambridge University Press, Cambridge, England.

Rapport, D. J., Costanza, R., McMichael, A. J., 1998. Assessing ecosystem health. Trends Ecol. Evol. 13, 397-402.

Redfield, A. C., 1958. The biological control of the chemical factors in the environment. Am. Sci. 46, 205-221.

Richey, J. E., Wissmar, R. C., Devol, A. H., Likens, G. E., Eaton, J. S., Wetzel, R. G., Odum, W. E., Johnson, N. M., Loucks, O. L., Prentki, R. T., Rich, P. H., 1978. Carbon flow in four lake ecosystems: a structural approach. Science 202, 1183-1186.

Rybarczyk, H., Elkaim, B., Ochs, L., Loquet, N., 2003. Analysis of the trophic network of a macrotidal ecosystem: the Bay of Somme (eastern channel). Estuar. Coast. Shelf Sci. 58, 405-421.

Sandberg, J., Elmgren, R., Wulff, F., 2000. Carbon flows in Baltic Sea food webs - a re-evaluation using a mass balance approach. J. Mar. Sys. 25, 249-260

Schramski, J. R., Gattie, D. K., Patten, B. C., Borrett, S. R., Fath, B. D., Thomas, C. R., Whipple, S. J., 2006. Indirect effects and distributed control in ecosystems: Distributed control in the environ networks of a seven-compartment model of nitrogen flow in the Neuse River estuary, USA-steady-state analysis. Ecol. Mod. 194, 189-201.
Schramski, J. R., Gattie, D. K., Patten, B. C., Borrett, S. R., Fath, B. D., Whipple, S. J., 2007. Indirect effects and distributed control in ecosystems: Distributed control in the environ networks of a seven-compartment model of nitrogen flow in the Neuse River estuary, USA - time series analysis. Ecol. Mod. 206, 18-30.

Shevtsov, J., Kazanci, C., Patten, B. C., 2009. Dynamic environ analysis of compartmental systems: a computational approach. Ecol. Mod. 220, 3219-3224.

Tilly, L. J., 1968. The structure and dynamics of Cone Spring. Ecol. Monogr. 38, 169-197.

Ulanowicz, R. E., 1986. Growth and Development: Ecosystems Phenomenology. Springer-Verlag, New York.

Ulanowciz, R. E., 1995. Trophic flow networks as indicators of ecosystem stress. In: Polis, G. A., Winemiller, K. O. (Eds.), Food Webs: Integration of Patterns and Dynamics. Chapman and Hall, NY, pp. 358-368.

Ulanowicz, R. E., Bondavalli, C., Egnotovich, M. S., 1997. Network analysis of trophic dynamics in south Florida ecosystem, FY 96: The cypress wetland ecosystem. Annual Report to the United States Geological Service Biological Resources Division Ref. No. [UMCES]CBL 97-075, Chesapeake Biological Laboratory, University of Maryland.

Ulanowicz, R. E., Bondavalli, C., Egnotovich, M. S., 1998. Network analysis of trophic dynamics in south Florida ecosystem, FY 97: The Florida Bay ecosystem. Annual Report to the United States Geological Service Biological Resources Division Ref. No. [UMCES]CBL 98-123, Chesapeake Biological Laboratory, University of Maryland.

Ulanowicz, R. E., Bondavalli, C., Heymans, J. J., Egnotovich, M. S., 1999. Network analysis of trophic dynamics in south Florida ecosystem, FY 98: The mangrove ecosystem. Annual Report to the United States Geological Service Biological Resources Division Ref. No.[UMCES] CBL 99-0073; Technical Report Series No. TS191-99, Chesapeake Biological Laboratory, University of Maryland.

Ulanowicz, R. E., Bondavalli, C., Heymans, J. J., Egnotovich, M. S., 2000. Network analysis of trophic dynamics in south Florida ecosystem, FY 99: The graminoid ecosystem. Annual Report to the United States Geological Service Biological Resources Division Ref. No. [UMCES] CBL 00-0176, Chesapeake Biological Laboratory, University of Maryland.

Ulanowicz, R. E., Puccia, C. J., 1990. Mixed trophic impacts in ecosystems. Coenoses 5, 7-16.

Urban, D., Keitt, T., 2001. Landscape connectivity: a graphtheoretic perspective. Ecology 82, 1205-1218.

Webster, J. R., Waide, J. B., Patten, B. C., 1975. Nutrient recycling and the stability of ecosystems. In: Howell, F. G., Gentry, J. B., Simth, M. H. (Eds.), Mineral cycling in southeastern ecosystems. Energy Research and Development Administration (ERDA) Symposium Series. Technical Information Center, Washington, D.C., USA.

Wootton, J. T., 1991. Direct and indirect effects of nutrients on intertidal community structure-variable consequences of seabird guano. J. Exp. Mar. Biol. Ecol. 151, 139-153.

Wootton, J. T., 1993. Indirect effects and habitat use in an intertidal community: Interaction chains and interaction modifications. Am. Nat. $141,71-89$ 
Table 1: Fifty empirically derived trophically-based ecosystem models.

\begin{tabular}{|c|c|c|c|c|c|c|}
\hline Model & units & $n^{\dagger}$ & $C^{\dagger}$ & $T S T^{\dagger}$ & $F C I^{\dagger}$ & Source \\
\hline Lake Findley & $\mathrm{gC} \mathrm{m}^{-2} \mathrm{yr}^{-1}$ & 4 & 0.38 & 51 & 0.30 & Richey et al. (1978) \\
\hline Mirror Lake & $\mathrm{gC} \mathrm{m}^{-2} \mathrm{yr}^{-1}$ & 5 & 0.36 & 218 & 0.32 & Richey et al. (1978) \\
\hline Lake Wingra & $\mathrm{gC} \mathrm{m}^{-2} \mathrm{yr}^{-1}$ & 5 & 0.40 & 1,517 & 0.40 & Richey et al. (1978) \\
\hline Marion Lake & $\mathrm{gC} \mathrm{m}^{-2} \mathrm{yr}^{-1}$ & 5 & 0.36 & 243 & 0.31 & Richey et al. (1978) \\
\hline Cone Springs & $\mathrm{kcal} \mathrm{m}^{-2} \mathrm{yr}^{-1}$ & 5 & 0.32 & 30,626 & 0.09 & Tilly (1968) \\
\hline Silver Springs & $\mathrm{kcal} \mathrm{m}^{-2} \mathrm{yr}^{-1}$ & 5 & 0.28 & 29,175 & 0.00 & Odum (1957) \\
\hline English Channel & $\mathrm{kcal} \mathrm{m}^{-2} \mathrm{yr}^{-1}$ & 6 & 0.25 & 2,280 & 0.00 & Brylinsky (1972) \\
\hline Oyster Reef & Kcal m${ }^{-2} \mathrm{yr}^{-1}$ & 6 & 0.33 & 84 & 0.11 & Dame and Patten (1981) \\
\hline Somme Estuary & $\mathrm{mgC} \mathrm{m} \mathrm{m}^{-2} \mathrm{~d}^{-1}$ & 9 & 0.30 & 2,035 & 0.14 & Rybarczyk et al. (2003) \\
\hline Bothnian Bay & $\mathrm{gC} \mathrm{m}^{-2} \mathrm{yr}^{-1}$ & 12 & 0.22 & 130 & 0.18 & Sandberg et al. (2000) \\
\hline Bothnian Sea & $\mathrm{gC} \mathrm{m}^{-2} \mathrm{yr}^{-1}$ & 12 & 0.24 & 458 & 0.27 & Sandberg et al. (2000) \\
\hline Ythan Estuary & $\mathrm{gC} \mathrm{m}^{-2} \mathrm{yr}^{-1}$ & 13 & 0.23 & 4,181 & 0.24 & Baird and Milne (1981) \\
\hline Baltic Sea & $\mathrm{mgC} \mathrm{m} \mathrm{m}^{-2} \mathrm{~d}^{-1}$ & 15 & 0.17 & 1,974 & 0.13 & Baird et al. (1991) \\
\hline Ems Estuary & $\mathrm{mgC} \mathrm{m} \mathrm{m}^{-2} \mathrm{~d}^{-1}$ & 15 & 0.19 & 1,019 & 0.32 & Baird et al. (1991) \\
\hline Swarkops Estuary & $\mathrm{mgC} \mathrm{m} \mathrm{m}^{-2} \mathrm{~d}^{-1}$ & 15 & 0.17 & 13,996 & 0.47 & Baird et al. (1991) \\
\hline Southern Benguela Upwelling & $\mathrm{mgC} \mathrm{m} \mathrm{m}^{-2} \mathrm{~d}^{-1}$ & 16 & 0.23 & 1,774 & 0.19 & Baird et al. (1991) \\
\hline Peruvian Upwelling & $\mathrm{mgC} \mathrm{m} \mathrm{m}^{-2} \mathrm{~d}^{-1}$ & 16 & 0.22 & 33,496 & 0.04 & Baird et al. (1991) \\
\hline Crystal River (control) & $\mathrm{mgC} \mathrm{m} \mathrm{m}^{-2} \mathrm{~d}^{-1}$ & 21 & 0.19 & 15,063 & 0.07 & Ulanowicz (1986); Ulanowciz (1995) \\
\hline Crystal River (thermal) & $\mathrm{mgC} \mathrm{m} \mathrm{m}^{-2} \mathrm{~d}^{-1}$ & 21 & 0.14 & 12,032 & 0.09 & Ulanowicz (1986); Ulanowciz (1995) \\
\hline Charca de Maspalomas Lagoon & $\mathrm{mgC} \mathrm{m}^{-2} \mathrm{~d}^{-1}$ & 21 & 0.13 & $6,010,331$ & 0.18 & Almunia et al. (1999) \\
\hline Northern Benguela Upwelling & $\mathrm{mgC} \mathrm{m}^{-2} \mathrm{~d}^{-1}$ & 24 & 0.21 & 6,608 & 0.05 & Heymans and Baird (2000) \\
\hline Neuse Estuary (early summer 1997) & $\mathrm{mgC} \mathrm{m} \mathrm{m}^{-1}$ & 30 & 0.09 & 13,826 & 0.12 & Baird et al. (2004b) \\
\hline Neuse Estuary (late summer 1997) & $\mathrm{mgC} \mathrm{m} \mathrm{m}^{-2} \mathrm{~d}^{-1}$ & 30 & 0.11 & 13,038 & 0.13 & Baird et al. (2004b) \\
\hline Neuse Estuary (early summer 1998) & $\mathrm{mgC} \mathrm{m} \mathrm{m}^{-2} \mathrm{~d}^{-1}$ & 30 & 0.09 & 14,025 & 0.12 & Baird et al. (2004b) \\
\hline Neuse Estuary (late summer 1998) & $\mathrm{mgC} \mathrm{m} \mathrm{m}^{-2} \mathrm{~d}^{-1}$ & 30 & 0.10 & 15,031 & 0.11 & Baird et al. (2004b) \\
\hline Gulf of Maine & g ww m $\mathrm{m}^{-2} \mathrm{yr}^{-1}$ & 31 & 0.35 & 18,382 & 0.15 & Link et al. (2008) \\
\hline Georges Bank & g ww m $\mathrm{m}^{-2} \mathrm{yr}^{-1}$ & 31 & 0.35 & 16,890 & 0.18 & Link et al. (2008) \\
\hline Middle Atlantic Bight & g ww $\mathrm{m}^{-2} \mathrm{yr}^{-1}$ & 32 & 0.37 & 17,917 & 0.18 & Link et al. (2008) \\
\hline Narragansett Bay & $\mathrm{mgC} \mathrm{m}{ }^{-2} \mathrm{yr}^{-1}$ & 32 & 0.15 & $3,917,246$ & 0.51 & Monaco and Ulanowicz (1997) \\
\hline Southern New England Bight & g ww $\mathrm{m}^{-2} \mathrm{yr}^{-1}$ & 33 & 0.03 & 17,597 & 0.16 & Link et al. (2008) \\
\hline Chesapeake Bay & $\mathrm{mgC} \mathrm{m} \mathrm{mr}^{-1}$ & 36 & 0.09 & $3,227,453$ & 0.19 & Baird and Ulanowicz (1989) \\
\hline St. Marks Seagrass, site 1 (Jan) & $\mathrm{mgC} \mathrm{m} \mathrm{m}^{-2} \mathrm{~d}^{-1}$ & 51 & 0.08 & 1,316 & 0.13 & Baird et al. (1998) \\
\hline St. Marks Seagrass, site 1 (Feb) & $\mathrm{mgC} \mathrm{m} \mathrm{m}^{-2} \mathrm{~d}^{-1}$ & 51 & 0.08 & 1,591 & 0.11 & Baird et al. (1998) \\
\hline St. Marks Seagrass, site 2 (Jan) & $\mathrm{mgC} \mathrm{m}^{-2} \mathrm{~d}^{-1}$ & 51 & 0.07 & 1,383 & 0.09 & Baird et al. (1998) \\
\hline St. Marks Seagrass, site 2 (Feb) & $\mathrm{mgC} \mathrm{m}^{-2} \mathrm{~d}^{-1}$ & 51 & 0.08 & 1,921 & 0.08 & Baird et al. (1998) \\
\hline St. Marks Seagrass, site 3 (Jan) & $\mathrm{mgC} \mathrm{m}^{-2} \mathrm{~d}^{-1}$ & 51 & 0.05 & 12,651 & 0.01 & Baird et al. (1998) \\
\hline St. Marks Seagrass, site 4 (Feb) & $\mathrm{mgC} \mathrm{m}^{-2} \mathrm{~d}^{-1}$ & 51 & 0.08 & 2,865 & 0.04 & Baird et al. (1998) \\
\hline Sylt Rømø Bight & $\mathrm{mgC} \mathrm{m} \mathrm{m}^{-2} \mathrm{~d}^{-1}$ & 59 & 0.08 & $1,353,406$ & 0.09 & Baird et al. (2004a) \\
\hline Graminoids (wet) & $\mathrm{gC} \mathrm{m}^{-2} \mathrm{yr}^{-1}$ & 66 & 0.18 & 13,677 & 0.02 & Ulanowicz et al. (2000) \\
\hline Graminoids (dry) & $\mathrm{gC} \mathrm{m}^{-2} \mathrm{yr}^{-1}$ & 66 & 0.18 & 7,520 & 0.04 & Ulanowicz et al. (2000) \\
\hline Cypress (wet) & $\mathrm{gC} \mathrm{m}^{-2} \mathrm{yr}^{-1}$ & 68 & 0.12 & 2,572 & 0.04 & Ulanowicz et al. (1997) \\
\hline Cypress (dry) & $\mathrm{gC} \mathrm{m}^{-2} \mathrm{yr}^{-1}$ & 68 & 0.12 & 1,918 & 0.04 & Ulanowicz et al. (1997) \\
\hline Lake Oneida (pre-ZM) & $\mathrm{gC} \mathrm{m}^{-2} \mathrm{yr}^{-1}$ & 74 & 0.22 & 1,638 & $<0.01$ & Miehls et al. (2009a) \\
\hline Lake Quinte (pre-ZM) & $\mathrm{gC} \mathrm{m}^{-2} \mathrm{yr}^{-1}$ & 74 & 0.21 & 1,467 & $<0.01$ & Miehls et al. (2009b) \\
\hline Lake Oneida (post-ZM) & $\mathrm{gC} \mathrm{m}^{-2} \mathrm{yr}^{-1}$ & 76 & 0.22 & 1,365 & $<0.01$ & Miehls et al. (2009a) \\
\hline Lake Quinte (post-ZM) & $\mathrm{gC} \mathrm{m}^{-2} \mathrm{yr}^{-1}$ & 80 & 0.21 & 1,925 & 0.01 & Miehls et al. (2009b) \\
\hline Mangroves (wet) & $\mathrm{gC} \mathrm{m}^{-2} \mathrm{yr}^{-1}$ & 94 & 0.15 & 3,272 & 0.10 & Ulanowicz et al. (1999) \\
\hline Mangroves (dry) & $\mathrm{gC} \mathrm{m}^{-2} \mathrm{yr}^{-1}$ & 94 & 0.15 & 3,266 & 0.10 & Ulanowicz et al. (1999) \\
\hline Florida Bay (wet) & $\mathrm{mgC} \mathrm{m} \mathrm{m}^{-2} \mathrm{yr}^{-1}$ & 125 & 0.12 & 2,721 & 0.14 & Ulanowicz et al. (1998) \\
\hline Florida Bay (dry) & $\mathrm{mgC} \mathrm{m}^{-2} \mathrm{yr}^{-1}$ & 125 & 0.13 & 1,779 & 0.08 & Ulanowicz et al. (1998) \\
\hline
\end{tabular}

${ }^{\dagger} n$ is the number of nodes in the network model, $C=L / n^{2}$ is the model connectance when $L$ is the number of direct links or energy-matter transfers, $T S T=\sum \sum f_{i j}+\sum z_{i}$ is the total system throughflow, and FCI is the Finn Cycling Index. 